\title{
Research on the English Translation of Chinese Public Signs Based on Face Theory
}

\author{
Xueqing Zhao \\ East China University of Science and Technology, Shanghai, China \\ Email: 1585789718@qq.com
}

How to cite this paper: Zhao, X.Q. (2021) Research on the English Translation of Chinese Public Signs Based on Face Theory. Open Access Library Journal, 8: e7391

https://doi.org/10.4236/oalib.1107391

Received: April 7, 2021

Accepted: May 8, 2021

Published: May 11, 2021

Copyright ( 2021 by author(s) and Open Access Library Inc.

This work is licensed under the Creative

Commons Attribution International

License (CC BY 4.0).

http://creativecommons.org/licenses/by/4.0/

(c) (i) Open Access

\begin{abstract}
The concept of face is a principle followed in human communication. The understandings of face toward different cultural groups are different. The different understandings toward face and maintenance strategies between China and western culture are also reflected in pubic signs. Thus, when translators translate Chinese public signs into English and the face of English readers is ignored, pragmatic errors will occur in the translation. Through a comparative analysis of face between Chinese and western culture, the paper explores different public signs in China and western countries caused by the face issues. Meanwhile, the paper tries to offer suggestions for the improvement on the translation methods and strategies of translating Chinese public signs into English.
\end{abstract}

\section{Subject Areas}

Linguistics

\section{Keywords}

The Comparison of Face Issues between China and Western Culture, The Comparison of Public Signs between China and Western Countries, Translation Methods and Strategies

\section{1. 中西 “面子理论” 的差异及特点}

\section{1. 中西对面子的研究综述}

1994 年, 中国著名人类学家胡先缙在《美国人类学家》上撰写了一篇文章, 首次把面子概念引入到西方。之后，美国著名学者戈夫曼在这一面子观念的 综合分析基础上，提出了一套 “面子理论”。戈夫曼认为，面子对所有人来 说都很重要, 因为它是交际双方必须遵守的一个重要原则。除此以外, 戈夫 
曼认为, 交际者想要别人尊敬自己, 需要先尊重别人的面子。可以看出, 戈 夫曼把面子视为神圣的、庄严的社交准则。他从社会学的角度分析了面子理 论, 并把 “面子” 定义为 “一个人在某个具体交际场合中, 通过采取言语动 作而为自己获得的正面的社会价值, 是按照社会所赞许的属性而创造的自我 形象” [1]。

1978 年, 英国人类学家布朗和勒文森发表了一篇《语言应用的普遍现象: 礼貌现象》的文章, 他们在文章中对 “面子” 进行了系统的研究, 并提出了

“面子保全论”。布朗和勒文森将 “面子” 定义为 “每一个社会成员意欲为 自己挣得的一种个人形象” 。他们将面子分为两种类型, 即积极面子和消极 面子。维护消极面子的人注重个性, 是不希望别人强迫自己, 他们希望自己 的行动不受干涉和阻碍且自己有行动的自由。维护积极面子的人是希望得到 别人的赞赏和喜爱。与此同时, 布朗和勒文森认为在交际过程中, 积极面子 和消极面子都会受到威胁, 因此大部分言语行为都是威胁面子的行为。例如, 在课堂教学中, 教师指名道姓的言语: Tom, you read the last paragrap, 增加 了威胁程度, 使学生的消极面子受损。这种指令言语使用过多, 可能会引起 学生的反感。利奇在其著作中阐述了关于礼貌的原则, 即得体准则、慷慨准 则、赞誉准则、谦逊准则、一致准则和同情准则, 这一准则是按照英国文化 的特点提出的。同时他认为, 各项准则在不同的文化中所产生的重要性是不 同的 [2]。斯宾塞认为面子和身份都与个人本身的某种特征相关, 包括个体原 因、与个体密切联系的的集体原因和个体所归于的集体因素都, 个体或集体 的特征就是面子与身份的联系的基础 [3]。

上世纪 30 年代, 鲁迅曾经撰写一篇文章名为《说面子》, 他认为中国人 要面子, 且面子是复杂的, 每一种身价就有一种面子。国学教育家大师林语 堂, 在其著作《中国人》中, 对于面子问题进行了详细而深入的分析研究。 他认为我们不能给自己的面子一个定义, 因为面子是无形且空虚的。胡先缙 从语义学理论分析的角度对面子问题进行了一个系统的研究, 他认为 “面子” 的含义是 “个人的声望和地位得到公众的一致认可” 。顾曰国在《礼貌、语 用与文化中》中详细地分析了面子学的理论, 并明确地提出了礼貌的基本原 则, 即以贬已为尊人的准则; 称呼规范; 文雅规范; 求同准则; 德、言、行 规范 [4]。翟学伟认为, 中国人的社会是情理社会, 人们在日常生活中倾向于 使用人情和面子, 因此放弃了规则、理性和制度, 得到的却是大量的社会资 源、非制度性的社会支持和庇护及以权势压人的日常权威[5]。

\section{2. 中国文化中的面子观}

在中国, 有很多耳熟能详的关于面子的俗语, 诸如 “人活一张脸, 树活 一张皮”、“好面子”、“要面子” 等。这些都反映了, 中国文化中面子对 于中国人的重要性。在中国文化中, 集体主义起着举足轻重的地位。首先, 纵观我国两千年封建时期的历史, 是完全建立在传统的农业和耕种基础上, 一代又一辈的中国农民被严重地束缚在这片土地上, 他们更加依赖这些土地 来进行生存和发展作息[6]。因此, 在这些土地上, 人与人之间都形成了紧密 的纽带, 人们可以团结、互助, 休戚与共, 亲朋好友通常居住在一处, 很少 
会迁移。其次，中国人一直以来都是坚持 “大一统” 或者 “大同” 的信仰。 从秦始皇灭六国统一天下到逐步加强政府和中央集权，处处表明统治者希望 能够通过统一的政治思想和制度巩固自己封建统治。因此，集体主义价值观 就是在这种背景下产生的。在这种群体中，人们以群体为中心，做事首先以 群体为重, 而个人的愿望、目标和隐私对于群体来说是处于第二位的, 因此 集体中的个人常通过贬低自己来突出群体或他人。所以中国人讲面子更多的 是注重集体的面子。另一方面，中国人的面子也是深受儒家的 “礼教” 思想。 儒家思想是中国民族优秀传统教育的主要内容, 它丰富了中国传统道德宝库。 儒家思想的核心包括仁、义、礼、智、信等，不以恶小而为之，不以善小而 不为; 凡是语言、动作、办事方式、做人尊严、人格等与提倡不符者, 都会 受到批评和谴责，为人们所不齿，因此好名声、好面子就保不住。基于此， 维护集体主义面子长期以来深入人心 $[7]$ 。中国人努力维护集体的面子，这种 积极的面子更多地接近于布朗和勒文森所提出的积极面子，即一种希望能够 得到其他人的一致赞同、接受和尊重, 并不是崇尚过分地满足其个人行为的 自由。

\section{3. 西方文化中的面子观}

与中国的面子观不同，西方文化中的面子观强调个人行动和个人自由不 受束缚以及个人的愿望得到满足。Hofstede 认为，西方的文化是个人主义。 西方早在文艺复兴中就声称人文主义, 强调个人的价值, 重视个人的自由, 强调个人的自我支配，控制和发展。在此之后，人文主义所强调的精神发展 成为 “自由” “民主” 思想。在西方的自由交往中，不尊重个人的自由、权 利和独立是粗鲁的, 反之则是礼貌的。例如, 在 2020 年西方国家新冠病毒爆 发时, 政府呼吁群众戴口罩、待在家里以及保持社交距离, 这些措施反而激 起了众怒。其中一个重要原因是因为西方国家的年轻人都崇尚自由, 他们认 为待在家里足不出户就行是禁锢自己的自由, 个人旅行和聚会自由则是宝贵 的资源和财富，即使是在流感疫情期间也绝对不该轻易抛弃。而对于现在的 中国人来说, 戴上口罩则表达了一种社会集体主义的核心价值观, 即人们通 过戴口罩，展现自己在疫情期间尽一份力，也是团结的一份子。戴口罩、保 持社交距离、足不出户等行为促成了中国人一种休戚与共、同担共责的感觉。 因此，与中国的积极面子观不同，西方人的消极面子观更加接近于布朗和勒 文森所提出的消极面子，即重视个人的权利和行动自由。

\section{2. 汉英公示语中的面子差异及翻译策略}

公示语是公共场所面向大众的语言文字，是城市文明程度的标志之一， 对塑造、展示和维护良好的对外形象有着重要意义, 其形式包括静态的标牌 公示语和动态的语音提示。公示语有指示、命令、感谢、提醒、宣传、告诫、 警示或禁止等作用[8]。

\section{1. 公示语的功能}

公示语不仅传达语言，同时也传达了一种文化，因为中西在面子观上的 
差异同样也能在汉英公示语中反映出来。公示语根据功能可分为四类, 即指 示性公示语、提示性公示语、限制性公示语和强制性标识语。

1）具有指示性的公示语旨在向公众提供一定的消息或者指引, 通常不要 求公众采取某种行动, 并没有涉及威胁公众积极面子或消极面子的言语。例 如: “Waiting Hall”、“Express”、“Shuttle Bus”、“临时售票区”等。

2) 具有提示性的公示语可以起到提示或者是告知的作用, 交际中的对象 可以根据所提供的信息和内容做出相应的行为, 这类公示语用途广泛。例如：

“Please do not leave personal belongings unattended”、“This is a smoke-free building with smoke-free grounds”、“此路不通” 等。

3）具有限制性的公示语应当对交际者的交际行为作出明确限制、约束。

例如：“闲人免进”、“保持安静”、“Staff Only” 等。

4）强制性的公示语的特点是指令性和语气比较强, 旨在用一种强制性的 方法和手段来要求有关交际的对象必须做出或必须采取某种措施。例如: “严 禁吸烟”、“严禁携带危险品进站”、“Police Line Do Not Pass”等。

由于指示性和提示性公示语的作用是向公众提供信息，对公众的面子几 乎不构成影响，因此本文将重点分析后两种公示语。

\section{2. 限制性公示语在汉英公示语中的差异及翻译策略}

限制性公示语可以限制、约束和要求公众的行为，因而在英语文化中， 限制性的公示语对社会公众的消极面子具有较大威胁性。因为一些西方人比 较注重保持和维护自己的一种消极面子, 即他们希望自己的言论和行动不被 任何人干涉，具有言论和行动的自由，而凡是违反这种意愿的行为就会对交 际者构成面子威胁。因此，相对于公众来说，权势地位较高的政府职能部门 或服务机构, 他们与公众的地位相等。而在中国, 由于中国人重集体轻个人 的传统，政府职能部门或服务机构的地位通常要比公众高[9]。因此对于这些 部门所发出的限制性公示语, 公众不会觉得自己被冒犯了。而如果把汉语限 制性的公示语按照字面意思翻译成英语，就会威胁外国游客的消极面子，可 能有损中国对外形象。下面将列举一些汉语公示语来探讨他们的英译策略。

例 1: 远离河边。

翻译 1: Stay away from the river.

翻译 2: Please stay away from the river.

布朗和勒文森提出,许多言语行为在实质上都是对面子本身进行了一种 威胁, 讲究礼貌就是为了能够减轻言语交际对于面子造成的一种威胁[7]。因 此当一个人的言语对别人的面子产生重大威胁时，应该适当采取一些非常有 礼貌的沟通手段, 以便能帮助人迅速达到自己预期中的目标。在汉语中, “请”、 “您好”、“谢谢”、“不客气” 等礼貌用语，可以帮助交际者营造一种亲 切友好的氛围。在英语中, 祈使句后面加上 “please”一词可以起到舒缓语气, 减轻对消极面子的威胁程度 [8]。例如, 在英国爆发新冠病毒期间, 英国海滨 小镇韦斯顿拉起了劝游客暂时不要来的横幅：Please stay away from RHB。在 英国一些地铁上，也随处可见一些劝导公众的公示语，这些公示语的构成大 
部分是由祈使句+please 构成, 诸如 “Please keep your distance”、“Please keep a safe social distance”、“Please wear your mask” 等。因此, 在汉语公示语 英译时, 译者可以入乡随俗, 套用译语中现有的习惯说法, 以使公示语的作 用达到预期目标。

例 2: 带病回乡，不肖子孙/传染爹娘，丧尽天良。

翻译 1: people who bring the virus back home are unworthy descendants.

翻译 2: Please protect yourself \&others from virus.

例 3: 串门就是互相残杀, 聚会就是自寻短见。

翻译 1: To visit is to kill each other and gathering means suicide.

翻译 2: Visiting and gathering are detrimental to each other.

新冠病毒爆发期间，正值中国春节，大家都去拜访亲戚可能会导致大规 模传染, 因此中国的一些小镇和小乡村的领导们, 使出浑身解数, 拉开横幅, 劝导大家少走动。而这种横幅如果直译成英语, 势必让对外国人造成误解, 他们会认为中国政府限制他们的行动自由, 对他们的行动自主权的侵犯, 并 且 “残杀” 这种词出现在横幅上, 对于不懂文化的外国人来说, 很难理解。 因此比起直译, 译者应当将横幅中的实际意思翻译出来, 以更直观且更礼貌 的方式表达出来。

例 4: 闲人免进。

翻译 1: Idlers is not allowed in this area.

翻译 2: Staff Only/Restricted area.

首先，译文 1 将 “闲人” 译成 “idlers”，是一种不礼貌的措辞，中文中 的 “闲人” 指的是与此区域无关的人员，而英文中 “idlers” 指的是游手好闲 者, 这会误导外国游客认为他们是游手好闲的人，从而造成误会。其次，这 种命令和请求的语气就是要求公众做出某种行为, 所以译 1 这样的公示语势 必会伤害外国游客的消极面子。译 2 中的翻译换了一种表达方式，语气更柔 和的同时清晰地传达了公示语的意思。

\section{3. 强制性公示语在汉英公示语中的差异及翻译策略}

强制性的公示话语是指要求社会公众必须做出的或者是不得做出某种行 为。强制性公示语是要求公众必须采取或不得采取某种行动。因此, 强制性 公示语对西方公众消极面子威胁最大，而对中国公众没有消极面子的威胁。 英语文化中强调个体、尊重个人自由和行动自由, 所以政府是不允许凌驾在 个人的头上的，因此由政府部门发出的强制性公示语就是在干涉公众的个人 自由。而在中国传统文化中，人们对权利有着根深蒂固的尊崇。老师对学生、 父母对儿女、长辈对晚辈、上司对下属、政府和机关对民众都有较高的权势, 前者可以命令后者，后者听从前者，因此来自前者的命令并不对后者构成面 子上的威胁, 反而这种命令具有威严性[9]。

例 1: 禁止践踏草坪。

翻译 1: Don't tread on the lawn.

翻译 2: Keep off the grass.

例 2: 禁止摘花。 
翻译 1: Don't pick flowers.

翻译 2: Take care of the flowers.

例 3: 禁止吸烟。

翻译 1: No Smoking.

翻译 2: Thank you for not smoking.

汉语强制性公示语通常以 “禁止”、“切勿” 等词开头，如果将其直译 成英文中的 “Don't”、“Do not”、“No + Ving” 等结构，尤其是在非危险 区域使用强制性公示语，会对外国游客的消极面子造成威胁。对于一些追求 平等和自由的西方群体和公众而言，这类强制性的公示话语严重地侵犯了他 们的合法权益。所以译者在翻译时应尽量避免生硬和直译，而应当采取更为 礼貌的说法，比如用 Thank you for...结构向外国游客委婉表达感谢，希望对 方配合或合作。此外，译者还可以用比委婉的表达方法来提醒外国游客。比 如, 比起直接告知对方不要摘花或者不要踩踏草坪，告知对方要照顾好花或 者远离草坪既没有损害对方的面子也更容易为对方接受。

\section{3. 结语}

中国已经走上了国际的大舞台，同时也吸引了很多外国游客前台旅游观 光。公示语作为对外宣传的一部分, 其重要性日益显著。由于面子和文化的 差异，所以在汉语中使用的公示语在英译的过程中，译者要考虑文化因素， 顺应译语读者的思维习惯，灵活采取翻译策略，以使公示语的作用达到预期 效果。

\section{Conflicts of Interest}

The author declares no conflicts of interest regarding the publication of this paper.

\section{References}

[1] Goffman, E. (1995) On Face-Work: An Analysis of Ritual Elements in Social Interaction. Psychiatry, 18, 213.

[2] Leech, G.N. (1983) Principles of Pragmatics. Long-man, London.

[3] Spencer-Oatey, H. (2007) Theories of Identity and the Analysis of Face. Journal of Pragmatics, 39, 639-660.

[4] 顾曰国. 礼貌、语用与文化[J]. 外语教学与研究, 1992(4): 10-17.

[5] 翟学伟. 人情、面子与权力的再生产——情理社会中的社会交换方式[J]. 社会学 研究, 2004(5): 48-57.

[6] 胡文仲. 跨文化交际与英语学习 [M]. 上海: 上海译文出版社, 1988.

[7] 郭峥嵘. 中西方文化中“面子”的比较和分析[J]. 忻州师范学院学报, 2011, 27(1): 74-78.

[8] 罗瑜珍. 从面子理论看公示语的语气意义与翻译策略[J]. 河南商业高等专科学校 学报, 2015, 28(3): 87-90.

[9] 李永红. 英汉公示语的“面子”问题[J]. 吉林省教育学院学报, 2008(6): 111-113. 


\section{Appendix (Abstract and Keywords in Chinese)}

\section{基于面子理论的汉语公示语的英译研究}

摘要: 面子观念是人类交际中需要遵循的一个原则, 不同文化的群体对 面子有着不同的理解。在汉英文化中, 人们对面子有不同的理解和维护策略, 这种文化差异也表现在汉英公示语中。因此, 在汉语公示语的英译过程中, 如果忽略英语读者的面子需求, 译文就会出现语用失误。本文对比分析了中 西 “面子理论” 的差异，通过面子差异探析汉英公示语的不同，对汉语公示 语的英译方法和策略提供一些建议。

关键词: 中西面子差异, 汉英公示语差异, 翻译方法和策略 